\title{
РЕТРОПЕРИТОНЕОСКОПИЧЕСКАЯ ЛИТОТОМИЯ В ЛЕЧЕНИИ ОБСТРУКТИВНОГО КАЛЬКУЛЕЗНОГО ПИЕЛОНЕФРИТА: КЛИНИКО- МОРФОЛОГИЧЕСКИЙ АНАЛИЗ
}

\author{
Вершинина А.А. ${ }^{1,3}$, Неймарк А.И. ${ }^{2}$, Ильинская Е.В. ${ }^{3}$, Исаченко С.И. ${ }^{3}$, Лушникова Е.Л. ${ }^{1}$ \\ ${ }^{1}$ ФБНУ «Институт молекулярной патологии и патоморфологии», Новосибирск, e-mail: pathol@inbox.ru; \\ ${ }^{2}$ ФБОУ ВО «Алтайский государственный медииинский университет» МЗ РФ, Барнаул, е-таіl: \\ urologagmu@mail.ru; \\ ${ }^{3}$ Муниципальное бюджетное лечебно-профилактическое учреждение «Городская клиническая больница № 1》, \\ Новокузнеик, е-mail: admin@hosplnkz.ru
}

Представлены результаты лечения 78 пациентов с обструктивным калькулезным пиелонефритом, которым была выполнена ретроперитонеоскопическая литотомия. Проанализированы также результаты лечения 26 пациентов, которым в первые сутки заболевания было проведено стентирование с целью восстановления оттока мочи из почки, а в дальнейшем - контактная литотрипсия. При бактериологическом исследовании мочи в обеих группах высеяны Escherichia coli, Enterococcus faecalis, Klebsiella, преобладала кишечная палочка. По данным патоморфологического анализа, в исследованных образцах почки доминировал острый тубулоинтерстициальный пиелонефрит (59\% случаев), в остальных случаях (37\%) выявлены признаки обострения хронического пиелонефрита. Острый тубулоинтерстициальный пиелонефрит характеризовался выраженным полнокровием, отеком стромы, выраженной, как правило, диффузной лейкоцитарной инфильтрацией (иногда с формированием апостем), выраженными дистрофическими и некробиотическими изменениями эпителия канальцев. Хронический пиелонефрит характеризовался большим разнообразием структурных изменений, так как склеротические процессы, как правило, сочетались с экссудативно-некротическими. По данным комплексного клинико-лабораторного и инструментального обследования, ретроперитонеоскопический метод в лечении пациентов с обструктивным калькулезным пиелонефритом является более эффективным и безопасным. К основным его преимуществам относится полное удаление конкремента без риска развития бактериотоксического шока, уменышение медикаментозной нагрузки и периода нетрудоспособности.

Ключевые слова: уролитиаз, обструктивный $\quad$ калькулезный
ретроперитонеоскопическая литотомия.

\section{RETROPERITONEOSCOPIC LITHOTOMY IN THE TREATMENT OF OBSTRUCTIVE CALCULOUS PYELONEPHRITIS: CLINICAL AND MORPHOLOGICAL ANALYSIS}

\author{
Vershinina A.A. ${ }^{1,3}$, Neymark A.I. ${ }^{2}$, Ilinskaya E.V. ${ }^{3}$, Isachenko S.I. ${ }^{3}$, Lushnikova E.L. ${ }^{1}$ \\ ${ }^{1}$ Institute of Molecular Pathology and Pathomorphology, Novosibirsk, e-mail: pathol@inbox.ru; \\ ${ }^{2}$ Federal State Budgetary Educational Institution of Higher Education «Altay State Medical University» of the Ministry \\ of Healthcare of the Russian Federation, Barnaul, e-mail: urologagmu@mail.ru; \\ ${ }^{3}$ Municipal budget therapeutic and prophylactic institution "City Clinical Hospital № 1», Novokuznetsk, e-mail: \\ admin@hosplnkz.ru
}

The results of treatment of 78 patients with obstructive calculous pyelonephritis, who performed retroperitoneoscopic lithotomy, were presented. The results of treatment of 26 patients who underwent stenting in the first day of the disease to restore the outflow of urine from the kidney, and subsequently contact lithotripsy, were also analyzed. In a bacteriological study of urine in both groups, Escherichia coli, Enterococcus faecalis, Klebsiella were revealed, and Escherichia coli prevailed. According to the pathomorphological examination, acute tubulointerstitial pyelonephritis $(59 \%$ of cases) dominated in the kidney samples, in other cases $(37 \%)$ signs of exacerbation of chronic pyelonephritis were found. Acute tubulointerstitial pyelonephritis was characterized by pronounced plethora, edema of the stroma, as a rule, by diffuse leukocyte infiltration (sometimes with formation of apostems), pronounced dystrophic and necrobiotic changes in tubular epithelium. Chronic pyelonephritis was characterized by a wide variety of structural changes, because sclerotic processes were combined with exudative-necrotic processes. According to the comprehensive clinical laboratory and instrumental examination, the retroperitoneoscopic method in the treatment of patients with obstructive calculous pyelonephritis is more effective and safe. Its main advantages include the complete removal of the calculus without the risk of development of bacterial shock, a decrease in the drug load and the period of incapacity for work.

Keywords: urolithiasis, obstructive calculous pyelonephritis, morphogenesis, retroperitoneoscopic lithotomy. 
Мочекаменная болезнь является одним из основных урологических заболеваний (занимает второе место, уступая первенство воспалительным заболеваниям). Проводимые исследования подтверждают, что заболеваемость уролитиазом неуклонно растет [8]. Грозным осложнением мочекаменной болезни, требующим оказания неотложной специализированной помощи, является острый обструктивный пиелонефрит. Выраженность клинико-морфологических проявлений острого обструктивного пиелонефрита может значительно варьироваться в зависимости от активности воспаления и продолжительности заболевания. Часто заболевание носит хронический характер, может сопровождаться периодическими обострениями, прогрессировать, осложняться недостаточностью почек.

При обструктивных формах пиелонефрита, как правило, необходима хирургическая коррекция, госпитализация в урологический стационар для экстренного восстановления пассажа мочи с целью предотвращения опасных для жизни осложнений - развития бактериотоксического шока [1]. Для этих целей проводят стентирование, катетеризацию почки или установку перкутанной нефростомы. Удаление камня проводится после купирования атаки острого пиелонефрита [5]. Чаще всего применяется контактная или дистанционная литотрипсия.

Установлено, что до 30-40\% камней почек инфицированы, микроорганизмы замуровываются в них или покрывают камни в виде пленки (биофильм) [6]. Присутствуя в подобных биопленках, микроорганизмы могут защититься от иммунной системы организма человека и действия антибиотиков [2; 7]. Литотрипсия сопряжена с активацией роста микроорганизмов, интегрированных в биопленку. Миграция бактерий и/или их токсинов в сосудистое русло может вызывать инфекционно-септические осложнения. Резидуальные фрагменты камней и биопленок на слизистой оболочке лоханки почки после операции рассматривают в качестве основных факторов риска рецидива камней [7]. Ретроперитонеоскопический метод, который относится к малоинвазивным, позволяет восстановить пассаж мочи из почки и удалить конкремент целиком одномоментно, без предварительного дренирования, не опасаясь развития бактериотоксического шока [3; 4; 9; $10]$.

При выполнении различных видов литотомии при обструктивном пиелонефрите большое значение имеет установление характера и выраженности повреждений почки для выбора более эффективных способов лечения и предотвращения развития почечной недостаточности. Для этого целесообразно проводить исследование биоптатов почки, полученных во время оперативных вмешательств.

Цель работы - изучить выраженность морфофункциональных изменений почки при мочекаменной болезни, сопровождающейся обструктивным калькулезным пиелонефритом, и 
оценить эффективность ретроперитонеоскопической литотомии в лечении мочекаменной болезни.

\section{Материал и методы исследования}

С 2011 по 2017 год на базе урологических отделений МБЛПУ «ГКБ № 1» г. Новокузнецка ретроперитонеоскопическим методом было прооперировано 78 пациентов (41

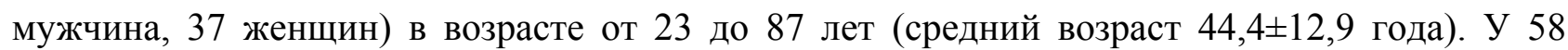
больных обструкция была на уровне верхней и средней третей мочеточника, у 20 человек конкремент находился в пиелоуретральном сегменте. Все камни были рентгенконтрастными, размерами от 9 до 25 мм (в среднем - 12,9 $\pm 4,8$ мм).

На предоперационном этапе всем пациентам проводили инструментальное, лабораторное обследование: ультразвуковое исследование почек и мочевыделительной системы, экскреторную урографию, общий анализ крови и мочи, исследование уровней мочевины и креатинина крови. Выполняли забор мочи для бактериологического исследования, проводили иммунологическое исследование крови. Оперативное вмешательство проводили в первые сутки госпитализации. Ретроперитонеоскопию выполняли под эндотрахеальной анестезией. Мочеточник вскрывали над камнем, который удаляли целиком. В случае локализации конкремента в пиелоуретральном сегменте производили разрез на лоханке.

У 27 пациентов во время операции выполняли биопсию почки в нижнем сегменте для проведения морфологического исследования. Биопсийный материал фиксировали в 10\%-ном нейтральном формалине и обрабатывали по стандартной методике для получения парафиновых срезов, которые окрашивали гематоксилином и эозином, по ван Гизону, ставили PAS-реакцию. Для получения полутонких срезов небольшие фрагменты почки фиксировали в 4\%-ном параформальдегиде, постфиксировали в 1\%-ной четырехокиси осмия, обезвоживали в серии спиртов возрастающей концентрации и заливали в смесь эпона и аралдита. Полутонкие срезы окрашивали 1\%-ным раствором азура II. Исследование проводили в универсальном микроскопе LeicaDM 4000B.

Для сравнения послеоперационных результатов проведен анализ 26 историй болезни пациентов (16 мужчин, 10 женщин), пролеченных в 2014-2017 гг., которым в первые сутки заболевания проводили стентирование для восстановления оттока мочи из почки. Через 2 нед. после купирования воспалительного процесса выполняли контактную литотрипсию. Размеры камней не превышали 1 см, все конкременты были рентген-контрастными. У 18 пациентов камень располагался в верхнем отделе мочеточника, у 8 - в среднем отделе мочеточника. Средний возраст пациентов существенно не отличался от возраста пациентов из основной группы (46,3 $\pm 13,8$ года). 
В обеих группах проводили иммунологическое исследование крови до и через 2 нед. после операции. В послеоперационном периоде пациенты получали симптоматическое лечение; антибактериальную терапию проводили цефалоспоринами III поколения.

\section{Результаты исследования и их обсуждение}

У пациентов обеих групп при поступлении регистрировались гипертермия, болевой симптом; общие анализы крови и мочи отражали развитие воспалительных процессов. Уровни мочевины и креатинина в сыворотке крови были повышены в основной группе у 28 человек, в группе сравнения - у 6 пациентов. При бактериологическом исследовании мочи в обеих группах были высеяны Escherichia coli, Enterococcus faecalis, Klebsiella, преобладала кишечная палочка. По данным ультразвукового исследования и экскреторной урографии было выявлено расширение мочевых путей до уровня стояния конкремента, выделительная функция почек не страдала.

Обструктивный (калькулезный) пиелонефрит является одним из наиболее частых осложнений мочекаменной болезни. По данным патоморфологического исследования, в исследованных образцах почки доминировал острый тубулоинтерстициальный пиелонефрит (59\% случаев). В 37\% случаев выявлены признаки обострения хронического пиелонефрита, в 4\% случаев в почках не было выявлено признаков воспалительных процессов.

При гистологическом исследовании чаще выявлялся (47\% случаев) серозно-гнойный (гнойный) пиелонефрит, серозный пиелонефрит встречался реже (29\% случаев). Во всех образцах почек регистрировались значительный отек интерстициальной соединительной (межуточной) ткани и выраженная, как правило, очагово-диффузная или диффузная, полиморфноклеточная инфильтрация (в одном случае - с примесью эозинофилов) (рис. 1). В некоторых случаях наблюдалась очаговая воспалительноклеточная инфильтрация с тенденцией к слиянию очагов и формированию апостем. Отмечалось распространение лейкоцитарной инфильтрации на соединительнотканную капсулу органа, которая часто была разрыхленной, отечной. Кровеносные сосуды были полнокровными, часто наблюдались массивные очаги свежих кровоизлияний и скопления гемосидерина, отражавшие наличие предшествовавших кровоизлияний. 


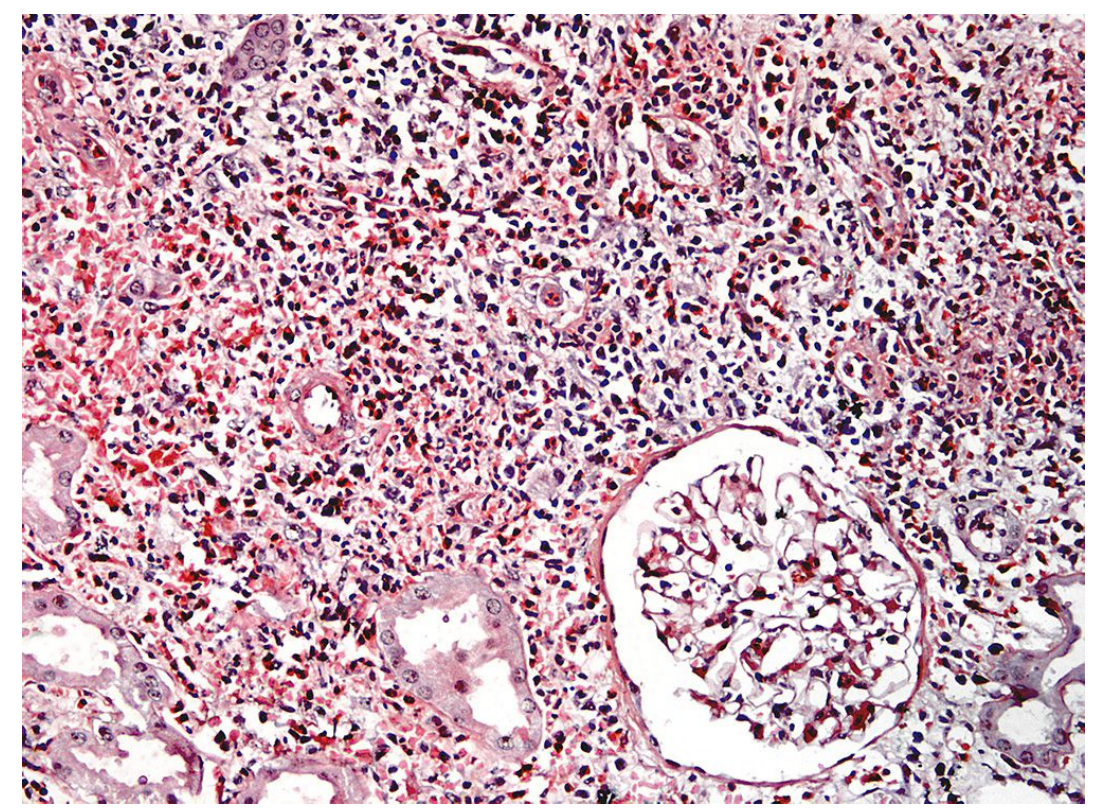

Рис. 1. Образец почки больной Б., 45 лет. Гнойный интерстициальный пиелонефрит.

Выраженная диффузная воспалительноклеточная инфильтрация интерстиция, массивные кровоизлияния. Окраска гематоксилином и эозином. Ув. 200

При пиелонефрите поражение клубочков по сравнению с канальцами, как правило, менее выражено, поскольку как при гематогенном, так и при уриногенном пути распространения инфекционные агенты первоначально проникают в мозговое вещество (тубулярный интерстиций), откуда затем постепенно мигрируют в корковое вещество. Наличие камней в мочеточниках и лоханке почки у всех прооперированных больных позволяет с большой вероятностью говорить об уриногенном пиелонефрите (восходящем пиелонефрите). При анализе состояния коркового вещества почек следует отметить, что в ряде случаев наблюдалась перикапсулярная лейкоцитарная инфильтрация, которая могла распространяться на клубочки. Изменения самих клубочков характеризовались значительным полиморфизмом. В разных срезах почки различалось от 8 до 30 клубочков. В большинстве клубочков отмечалось выраженное полнокровие капилляров, отек капсулы Боумена-Шумлянского, иногда значительный (рис. 1). Часть клубочков выглядели запустевшими.

Эпителий проксимальных и дистальных канальцев характеризовался в большинстве случаев выраженными дистрофическими изменениями, местами вплоть до некробиотических, частично был слущен. В просвете многих канальцев встречались эритроциты и лейкоциты. Просветы некоторых почечных канальцев были заполнены умеренно эозинофильными зернистыми массами, а также эозинофильным коллоидоподобным веществом (эозинофильными цилиндрами), в котором различались единичные лейкоциты. Совокупность этих изменений отражает выраженные деструктивные 
изменения тубулярного аппарата почек.

Хронический пиелонефрит характеризовался большим разнообразием структурных изменений, так как склеротические процессы, как правило, сочетались с экссудативнонекротическими. В ткани почки регистрировались морфологические проявления хронического воспаления, основной характеристикой которого было разрастание соединительной ткани; наблюдалась инкапсуляция абсцессов и макрофагальная резорбция гнойно-некротических масс. Эпителий канальцев характеризовался выраженными дистрофическими и в ряде случаев некробиотическими изменениями. Вокруг канальцев с явлениями выраженной дистрофии и атрофии формировались утолщенные соединительнотканные прослойки (рис. 2). Сохранившиеся канальцы часто были резко растянутыми, эпителий их был уплощен, частично слущен, просветы в ряде случаев заполнены хлопьевидным или густым коллоидоподобным содержимым (эозинофильными цилиндрами). Почка по своему строению в некоторых случаях напоминала щитовидную железу, т.е. отмечалась «тиреоидизация» почки.

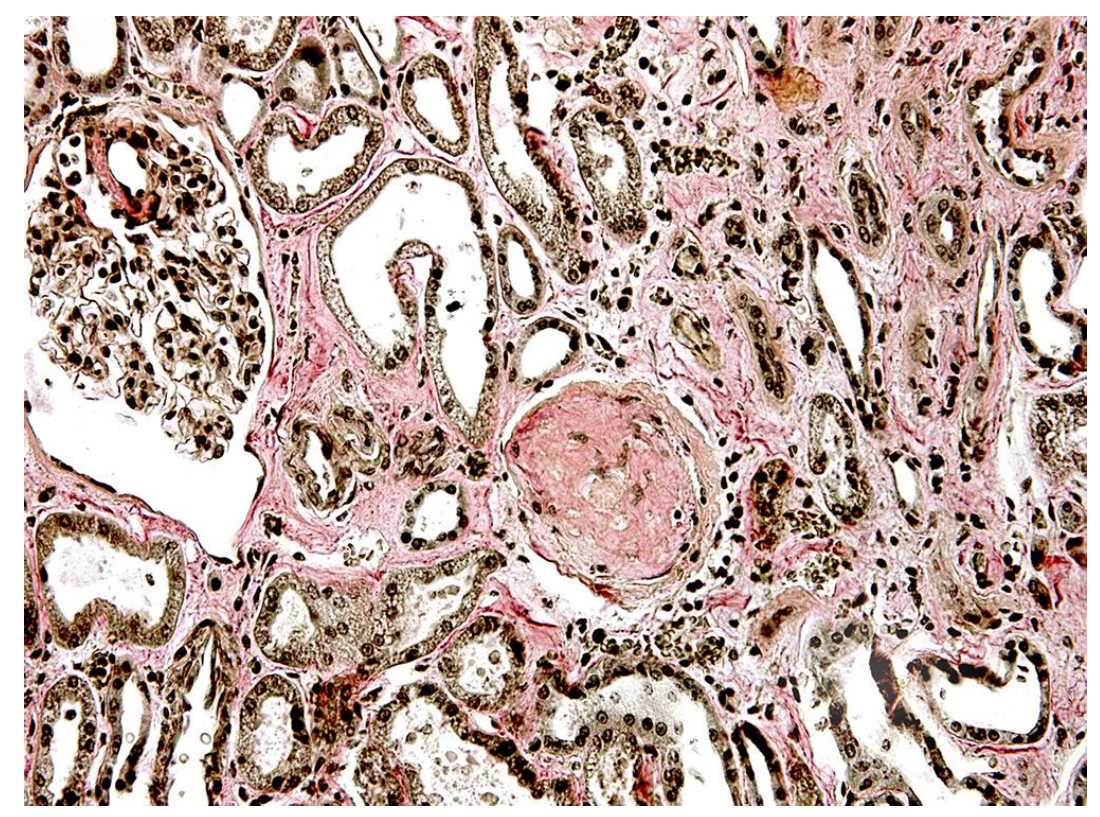

Рис. 2. Образец почки больной А., 45 лет. Склероз клубочка и выраженный склероз интерстищиальной ткани, скудная лейкоцитарная инфильтращия при обострении хронического пиелонефрита. Окраска по ван Гизону. Ув. 200

При хроническом нефрите отмечались более выраженные изменения коркового вещества. Примерно треть клубочков были склерозированными. В зоне склерозированных клубочков наблюдались участки перигломерулярного склероза (рис. 3), в некоторых случаях в части клубочков наблюдался перикапиллярный склероз. Отмечались выраженный склероз стромы, умеренная диффузная и мелкоочаговая мононуклеарная инфильтрация.

Для хронического пиелонефрита характерными были значительные изменения 
артериол: выраженный интраваскулярный и периваскулярный фиброз, гиперэластоз (мультипликация эластических мембран).

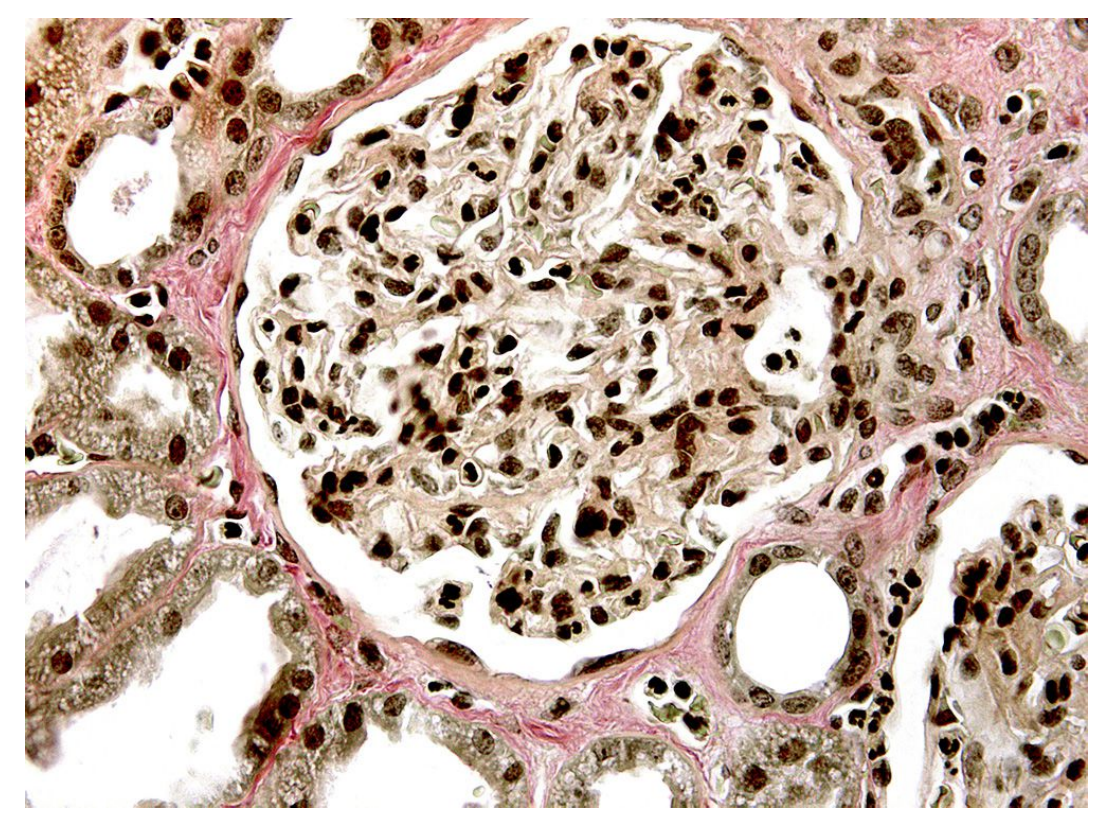

Рис. 3. Образеи почки больной А., 45 лет. Перигломерулярный склероз. Окраска по ван

Гизону. Ув. 400

Столь выраженные воспалительные изменения тубулоинтерстициального компартмента почки при остром пиелонефрите и значительные морфофункциональные изменения мозгового и коркового вещества при хроническом процессе на фоне уролитиаза обусловливают необходимость срочных хирургических манипуляций, направленных на устранение обструкции мочевыводящих путей. Применение ретроперитонеоскопической литотомии в основной группе было успешным у всех пациентов, конверсий не было. Все пациенты активизировались в первые сутки после операции. Нормализация температуры тела в послеоперационном периоде в первые сутки наступала у 42 человек, во вторые сутки у 27 человек, на третьи сутки - у 5 человек, на четвертые сутки - у 4 человек. Показатели общего анализа крови приходили в норму через 3 суток (в среднем); лейкоцитурия исчезла у 50 пациентов. Показатели мочевины и креатинина крови нормализовывались через 1-4 суток после операции. Среднее число послеоперационных койко-дней составило 8.

В группе сравнения срок первой госпитализации составил в среднем 7 суток. Нормализация температуры тела после стентирования почки в первые сутки отмечена у 7 человек, во вторые сутки - у 12 человек, на третьи сутки - у 5 человек, на четвертые сутки у 2 человек. Общий анализ крови нормализовался в период от 1 до 12 суток (в среднем через 4,5 суток). Показатели мочевины и креатинина крови нормализовывались через 3 суток от начала лечения. После купировании атаки пиелонефрита пациенты проходили амбулаторное лечение; вторую госпитализацию проводили через 21,5 суток (в среднем) с 
момента первого обращение в стационар. У всех пациентов при повторном поступлении в стационар выявлено повышение уровней лейкоцитов и эритроцитов в моче.

Несмотря на проводимую в стационаре и на амбулаторном этапе антибактериальную терапию (с учетом чувствительности микроорганизмов), в моче были выделены те же возбудители, что и на первичном этапе. У 5 человек в послеоперационном периоде зарегистрирована повторная атака острого пиелонефрита. Размер конкрементов у этих 5 пациентов был наибольшим в группе и составил 1,0 см, что потребовало большего количества времени для его дробления. Общий срок нетрудоспособности без учета амбулаторного этапа после второй госпитализации в среднем составил 31 день по сравнению с 8 днями в основной группе. Медикаментозная нагрузка была значительно выше по сравнению с пациентами, которых прооперировали ретроперитонеоскопическим методом.

В иммунограммах пациентов обеих групп до операции отмечалось повышение всех исследованных показателей иммунитета, что говорило в пользу воспалительного процесса в организме. Через 2 недели после обращения в стационар в основной группе все показатели приходили в норму, в то время как в группе сравнения они оставались повышенными.

32 пациента из основной группы были приглашены для обследования через 3-6 лет после операции. Целью обследования было выявление или исключение наличия стриктуры мочеточника в месте проведения ретроперитонеоскопической уретеролитотомии. Проводилось ультразвуковое исследование и экскреторная урография. Ни у одного из пациентов стриктура не была выявлена.

\section{Заключение}

Обструктивный калькулезный пиелонефрит, по данным проведенного патоморфологического анализа, при остром течении характеризуется значительными воспалительными изменениями тубулоинтерстициального компартмента почки с развитием очагово-диффузной или диффузной лейкоцитарной инфильтрации интерстициальной ткани почки (вплоть до формирования апостем). Для хронического пиелонефрита характерно развитие выраженного интерстициального фиброза как в мозговом, так и в корковом веществе при умеренной (или скудной) лимфогистиоцитарной инфильтрации интерстициальной ткани. Выявление примерно в 40\% случаев хронического пиелонефрита выраженных склеротических изменений коркового вещества почки обусловливает необходимость проведения комплексных клинико-морфологических исследований с целью выбора в дальнейшем наиболее эффективных методов лечения, а также разработку таких методов. Столь выраженные морфофункциональные изменения почки обусловлены нарушениями пассажа мочи и восходящей инфекцией, колонизирующей камни в мочевыводящих путях (в ряде случаев длительной). Результаты бактериологического 
исследования мочи пациентов из группы сравнения до литотрипсии и после проведения стентирования свидетельствуют о том, что элиминация микроорганизмов без избавления от конкремента невозможна. Важно подчеркнуть, что необходимо добиваться удаления камней целиком, без оставления резидуальных фрагментов.

Применение ретроперитонеоскопической литотомии при обструктивном калькулезном пиелонефрите эффективно и безопасно, позволяет удалять конкременты целиком (stonefree), не оставляя резидуальных фрагментов. Не требуется предварительного дренирования полостной системы почки, восстановление пассажа мочи и удаление конкремента проводится одновременно, без риска развития бактериотоксического шока. Рекомендуемый размер конкремента для данного метода - 1 см и более. Доступ позволяет локализовать возможные уриномы и гематомы в забрюшинном пространстве. Значительно сокращаются сроки нетрудоспособности и медикаментозная нагрузка на пациента.

\section{Список литературы}

1. Аляев Ю.Г., Еникеев Д.В. Принципы лечения острого калькулезного пиелонефрита // Саратовский научно-медицинский журнал. - 2011. - Т. 7, № S2. - С. s115.

2. Вощула В.И., Лыш Е.Я., Станкевич С.И. Инфекция в этиопатогенезе мочекаменной болезни // Медицинские новости. - 2007. - № 11. - С. 113-118.

3. Жумагалиев А.А., Усупбаев А.И. Ретроперитонеоскопические операции при гнойновоспалительных заболеваниях почек с различной степенью тяжести эндотоксикоза // Урология. - 2011. - № 5. - С. 84-88.

4. Кадыров 3.А., Торосьянц А.С., Нусратуллоев И.И., Сулейманов С.И. Ретроперитонеоскопическая уретеролитотомия при обструктивном пиелонефрите // Медицинский вестник Башкортостана. - 2001. - № 2. - С. 88-90.

5. Мартов А.Г., Фатихов Р.Р., Ергаков Д.В., Корниенко С.И. Трансуретральная контактная литотрипсия в лечении камней почек // Урология. - 2008. - № 6. - С. 70-75.

6. Перепанова Т.С., Козлов Р.С., Руднов В.А., Синякова Л.А. Антимикробная терапия и профилактика инфекций почек, мочевыводящих путей и мужских половых органов // Федеральные клинические рекомендации. - М., 2015. - 50 с.

7. Раджабов У.А., Перепанова Т.С. Метафилактика инфекционных камней почек после перкутанной нефролитотрипсии // Экспериментальная и клиническая урология. - 2015. № 2. - C. 80-83.

8. Шадеркина В.А., Болотова Е.В. Мочекаменная болезнь в мире // Дайджест урологии. - 2012. - № 2. - C. 60-64. 
9. Cezarino B.N., Park R., Moscardi P.R. et al. Retroperitoneoscopic pyelolithotomy: a good alternative treatment for renal pelvic calculi in children // Int. Braz. J. Urol. - 2016. - Vol. 42 (6). P. 1248.

10. Chipde S.S., Agrawal S. Retroperitoneoscopic pyelolithotomy: a minimally invasive alternative for the management of large renal pelvic stone // Int. Braz. J. Urol. - 2014. - Vol. 40 (1). - P. 123-124. 